\title{
La Unión Europea como marco de configuración de las políticas sociales y de discapacidad
}

\section{The European Union as the framework for setting social and disability policies}

\section{Palabras clave}

Unión Europea, política social europea, política europea de discapacidad, pilar social, no discriminación, acción positiva, empleo de personas con discapacidad, accesibilidad.

\section{Keywords}

European Union, European social policy, European disability policy, social pillar (the European pillar of social rights), nondiscrimination, positive action, employment of people with disabilities, accessibility.

\section{Introducción}

La política social es competencia compartida entre la Unión Europea (UE) y los Estados miembros, pero de acuerdo con el principio de subsidiariedad las competencias de la UE en materia social se limitan a "apoyar y complementar las actividades de los Estados miembros" y, en el caso de nuestro país, también de las comunidades autónomas. Es a ellos pues a los que les debe corresponder los mayores esfuerzos. El objeto de este artículo es, tal como su título indica, elevarse al nivel europeo, en tanto que marco general que tiene su relevancia a la hora de la configuración de las políticas sociales a nivel nacional y regional, y que además puede servir como fuente de inspiración para los ordenamientos jurídicos nacionales.

A esos efectos lo estructuraré como sigue: comenzaré analizando la competencia de la UE en materia de política social, incluyendo algunas pinceladas históricas. No me remontaré demasiado en el tiempo, sino que miraré

1. Este artículo procede de la intervención del autor en la apertura como conferencia magistral del Programa de Doctorado Derecho y Ciencias Sociales. Curso 2018-2019. UNED (Escuela Internacional de Doctorado). Madrid.
Miguel Ángel Cabra de Luna $<$ mcabradeluna@fundaciononce. es>

Fundación ONCE. España

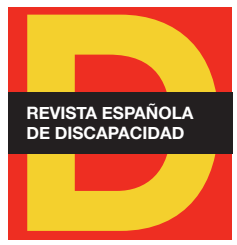

Para citar:

Cabra de Luna, M. A. et al. (2019): "La Unión Europea como marco de configuración de las políticas sociales y de discapacidad". Revista Española de Discapacidad,

7 (I): 221-240.

Doi: <https://doi.org/10.5569/23405104.07.01.11> 
al pasado reciente (la agenda social renovada), y al presente y futuro, que no es otro que la implementación del pilar europeo de derechos sociales. En ambos casos comenzaré proporcionando la visión global para posteriormente poner el foco en la perspectiva de la discapacidad.

Daré unos datos básicos sobre las personas con discapacidad:

- En la Unión Europea hay 80 millones de personas con discapacidad (16\%) de la población europea), de los cuales cuatro millones son españoles.

- El perfil de la discapacidad ha variado en las últimas décadas y particularmente en España:

- El $70 \%$ de las personas con discapacidad en edad laboral tienen una discapacidad sobrevenida. Sólo el $30 \%$ son de origen congénito.

- Más del $65 \%$ de la personas con discapacidad son mayores de 60 años.

Desarrollaré en mi artículo un análisis jurídico, pero también económico, en un doble frente:

- El empleo es la mejor fórmula de inclusión social.

- Las personas con discapacidad constituyen en gran medida un nicho de mercado sin explotar en su integridad; son trabajadores en número importante, son consumidores y nuevos clientes por atraer. $\mathrm{O}$ dicho de otra forma, la discapacidad/accesibilidad es una ventaja competitiva de primera magnitud a tener en cuenta por el mundo empresarial y máxime en mercados maduros como es el de la Unión Europea. Pensemos por ejemplo en el turismo.

\section{La política social en el proceso de integración europeo}

Cuando fue creada la Unión Europea en 1957, entonces denominadas las Comunidades Europeas, la dimensión social tuvo un protagonismo muy escaso, limitándose a provisiones relativas a facilitar la movilidad laboral, que fue desde el principio una de las libertades sacrosantas del proceso de integración europeo. Así, se abordaban sobre todo cuestiones de coordinación de los sistemas de seguridad social. El primer reglamento a estos efectos data de 1958, apenas un año después de la firma del Tratado de Roma. En los años 70 se empezó a tratar la cuestión de la no discriminación, pero desde la perspectiva de igualdad de género y de la igualdad salarial entre hombres y mujeres. En 1975 se adoptó la llamada en la jerga comunitaria "Equal Pay Directive", directiva "relativa a la aplicación del principio de igualdad de retribución entre los trabajadores masculinos y femeninos". Fue a finales de los años 80 y en los 90 cuando, con la profundización del mercado interior, la parte social comenzó a recibir mayor protagonismo en Bruselas. Primero con el Acta Única Europea adoptada en 1986 que aparte de dar un empujón importante a la creación del llamado "mercado único", establecía también mecanismos de coordinación de las políticas sociales de países miembros, que en aquellos años eran doce, tras la adhesión de España y Portugal. Fue seguido por la adopción en 1992 con el Tratado de Maastricht del Capítulo Social que exigía a los Estados miembros una mayor coordinación en materia de política social y la adopción de políticas sociales comunes. 
En paralelo, a mediados de los años 90, comenzó también a surgir un consenso acerca de la necesidad de que la Unión Europea, apremiada por el Parlamento Europeo y la sociedad civil, se enfrentase a la discriminación en una serie de campos adicionales, entre ellos la discriminación por razón de discapacidad.

Fue el Tratado de Ámsterdam, que entró en vigor en 1997, el que consagró a nivel comunitario el principio de no discriminación por motivos de sexo, raza u origen étnico, religión o creencias, discapacidad, edad u orientación sexual, permitiendo a la UE legislar en la materia. Así, su artículo 13, establecía que: "El Consejo, por unanimidad, a propuesta de la Comisión y previa consulta al Parlamento Europeo, podrá adoptar acciones adecuadas para luchar contra la discriminación por motivos de sexo, de origen racial o étnico, religión o convicciones, discapacidad, edad u orientación sexual".

En virtud de ese fundamento jurídico proporcionado por el artículo 13, se adoptó en el año 2000 un paquete integrado de medidas de lucha contra la discriminación, entre los que cabe destacar las siguientes directivas:

- Directiva 2000/43/CE sobre igualdad de trato independientemente del origen racial o étnico de las personas, tanto en el ámbito del empleo y la ocupación, como en la protección social, los beneficios sociales, la educación y el acceso a bienes y servicios, incluida la vivienda

- Directiva 2000/78/CE, marco general para la igualdad de trato en el empleo y la ocupación.

Las mismas formaban parte de un programa de acción más amplio en materia de no discriminación, que incluía una serie de medidas complementarias.

Unos años después, en 2004, se adoptó la Directiva 2004/113 sobre la implementación del principio de igualdad de trato entre hombres y mujeres en el acceso a bienes y servicios, y dos años después, la Directiva 2006/54 relativa a la aplicación del principio de igualdad de oportunidades e igualdad de trato entre hombres y mujeres en asuntos de empleo y ocupación, que venía a refundir todas las disposiciones anteriores en la materia, cerraban el sistema europeo de protección frente a la discriminación por razón de género.

Posteriormente, el artículo 13 fue modificado por el Tratado de Niza (2000), con el fin de permitir la adopción de medidas de incentivos por mayoría cualificada del Consejo. Mientras, las medidas legislativas seguían requiriendo aprobación por unanimidad en el Consejo, a pesar de las propuestas por parte de la Comisión para pasar a un sistema de mayoría cualificada y del intenso lobby realizado desde el sector social. Cabe señalar que el requisito de la unanimidad es uno de los elementos de bloqueo de futuros avances en la materia, como lo prueba que la propuesta de directiva de igualdad de trato formulada por la Comisión en 2008 para extender el principio de igualdad de oportunidades a todos los grupos desfavorecidos a ámbitos como la educación, la sanidad, la vivienda o la protección social (propuesta de directiva por la que se aplica el principio de igualdad de trato entre las personas independientemente de su religión o convicciones, discapacidad, edad u orientación sexual, $\operatorname{COM(2008)~} 426$ final, 2 de Julio de 2008) lleva una década bloqueada en el Consejo, sin verdaderas perspectivas de que la cosa cambie y pueda convertirse en derecho positivo. El Tratado de Lisboa (adoptado en diciembre de 2009) no cambió la situación, aunque sí que supuso un cierto avance en la medida que establece el carácter vinculante de la Carta de Derechos Fundamentales. La misma incluyó un amplio catálogo de derechos (sensiblemente más amplio por ejemplo que el incluido en la Constitución Española), todos ellos ya contemplados en diversos convenios e instrumentos legislativos, pero a los que se otorga rango constitucional. 
Desde principios del siglo XXI se puso también en práctica el llamado método abierto de coordinación, que es el instrumento de coordinación de políticas entre los Estados miembro de la UE que permite actuar a nivel europeo en áreas en las cuales la UE no puede legislar ya que no son de su competencia y que se basa en el intercambio de buenas prácticas y en la realización de evaluaciones por pares.

Hay que señalar también que las distintas iniciativas europeas en el ámbito social se plasmaron/agruparon en diversos planes y estrategias, como la Agenda Social, la Agenda Social Renovada o la Estrategia Europea de Empleo, por citar algunas.

\section{Recapitulación histórica de la política europea de discapacidad}

Pues bien, una vez realizada la recapitulación sobre la política social en sentido amplio comenzamos con la relativa a la política europea de discapacidad. Lo primero de todo que hay que decir es que hablar de la discapacidad en la Unión Europea no es tarea fácil. Detrás de esa expresión se esconde una gran diversidad de realidades. Diversidad que se vio incrementada considerablemente tras las sucesivas adhesiones de los países del Este (2004 y 2009).

No hemos de olvidar que a nivel de la UE no existe una definición común de la discapacidad. Así, las definiciones y los criterios utilizados para determinar la existencia de una discapacidad difieren considerablemente en los 28 (pronto 27) Estados miembros, lo que desgraciadamente constituye un obstáculo importante para el reconocimiento mutuo de las decisiones nacionales en materia de discapacidad, y en particular para la elegibilidad en el acceso a servicios, prestaciones e instalaciones específicas.

Sin embargo, es incuestionable que detrás de esa diversidad se esconden también una serie de rasgos y una realidad comunes, que merecen un enfoque paneuropeo de la discapacidad.

Aunque los tratados comunitarios no otorgan a la UE ni los poderes ni los instrumentos necesarios para la instauración de una verdadera política común en la materia, sin embargo la misma se antoja como necesaria en una Europa ampliada en la que las personas con discapacidad suponen un $15 \%$ de la población, esto es, alrededor de 80 millones de ciudadanos: "la minoría mayoritaria" o "los ciudadanos invisibles", como se les conoce.

Como dije anteriormente en sus orígenes la Comunidad Económica Europea comenzó a definir una política de no discriminación bastante limitada, poniendo únicamente el énfasis en la promoción de la igualdad entre hombres y mujeres. También como comentaba anteriormente, no fue hasta mediados de los años 90 cuando surgió un consenso acerca de la necesidad de que la Unión Europea, apremiada por el Parlamento Europeo y la sociedad civil, se enfrentase a la discriminación en una serie de campos adicionales, entre ellos la discriminación por razón de discapacidad.

Como hemos visto, fue el Tratado de Ámsterdam, el cual entró en vigor en 1997, el que autorizó por primera vez a la Unión Europea, a través de su artículo 13, a adoptar medidas para luchar contra la discriminación 
de las personas con discapacidad, siendo esta, de hecho, la primera referencia específica de los tratados a la 'discapacidad'. Dicho artículo proporcionaba una base para abordar situaciones de discriminación múltiple, mediante el establecimiento de una política y un enfoque legal común para los distintos aspectos de la discriminación, incluyendo una definición igual para todos, sin dejar de reconocer los retos específicos a los que se enfrenta cada grupo.

La discapacidad recibió atención especial en el paquete integrado de medidas de lucha contra la discriminación adoptado en 1999 y en la propuesta de directiva en el ámbito del empleo y la ocupación que prohibía la discriminación por cualquiera de los motivos que figuran en el artículo 13 y el programa de acción en materia de no discriminación, que incluía una serie de medidas complementarias. Dicha norma fue transpuesta al ordenamiento jurídico español mediante la Ley de igualdad de oportunidades, no discriminación y accesibilidad universal de las personas con discapacidad (Ley 51/2003, de 2 de diciembre). Es este un buen ejemplo del impacto de la UE en los ordenamientos jurídicos nacionales. Hoy Texto Refundido de la Ley General de Derechos de las Personas con Discapacidad y de su Inclusión Social (2007).

Volviendo de nuevo hacia atrás en el tiempo, hay que recordar que un año antes del Tratado de Ámsterdam se había publicado el primer documento de la UE que abordaba específicamente la discapacidad. Se trataba de la Comunicación de la Comisión Europea sobre la igualdad de oportunidades de las personas con discapacidad (Comunicación de la Comisión sobre la igualdad de oportunidades de las personas con minusvalía. Una nueva estrategia comunitaria en materia de minusvalía), que confirmaba a nivel comunitario la transición que se había ido produciendo durante las tres décadas anteriores del modelo médico de la discapacidad (más paternalista y que hace hincapié en la discapacidad en sí) al modelo social que argumenta que es la sociedad la que crea obstáculos y genera una serie de actitudes y prejuicios que son los que nos hacen percibir la discapacidad de las personas y los que nos impiden que dichas personas gocen de las mismas oportunidades que las personas sin discapacidad. Asimismo, dicha comunicación pasará a la historia por haber sido el primer instrumento a nivel europeo que introdujo el concepto del mainstreaming de la discapacidad, consistente en la transversalización de la dimensión de la discapacidad en todas las políticas europeas. En otras palabras, no se trata solo de aprobar legislación específica para las personas con discapacidad sino de asegurarse de que todas las iniciativas políticas y legislativas a la hora de ser diseñadas y aplicadas tengan en cuenta las especificidades de las personas con discapacidad.

Pues bien, esa transición y cambio de paradigma quedó simbólicamente consagrada posteriormente cuando en 2002, coincidiendo con la presidencia española de la UE, se adoptó la Declaración de Madrid, resultante del consenso alcanzado entre el movimiento de la discapacidad europeo, la presidencia española y la Comisión Europea, y a la que se adhirieron numerosas instituciones públicas y privadas, entre ellas el Parlamento Europeo. En este sentido me siento particularmente (y creo que legítimamente) orgulloso de que nuestra organización, la Fundación ONCE, fuese una de las precursoras de dicha iniciativa.

Aunque la discapacidad se ha venido abordando a nivel comunitario a través de distintos programas, no fue hasta 2003 cuando por primera vez la Unión Europea se dotó de un plan de acción específicamente dirigido a las personas con discapacidad. El mismo fue el resultado natural de la declaración de 2003 como Año Europeo de las Personas con Discapacidad.

Creo que se puede afirmar que el Año Europeo de las Personas con Discapacidad marcó un antes y un después en el proceso de definición de una política más ambiciosa y coordinada en materia de discapacidad a nivel europeo. 
A nivel español el Año Europeo también sirvió como acicate para la adopción de nuevas iniciativas. Así, por ejemplo, en España se diseñó un plan de acción específico para las personas con discapacidad (2003-2007), un nuevo plan nacional sobre accesibilidad (2004-2012) y un plan de empleo para las personas con discapacidad. En el ámbito legislativo se promulgaron dos nuevas leyes: una, ya mencionada anteriormente, en materia de igualdad de oportunidades y lucha contra la discriminación (a través de la que se transponían las directivas sobre no discriminación aprobadas en el año 2000 (Ley 51/2003, de 2 de diciembre, de igualdad de oportunidades, no discriminación y accesibilidad universal de las personas con discapacidad), de las que también he hablado con anterioridad, y otra sobre los derechos económicos y de sucesión de las personas con discapacidad (Ley 41/2003, de 18 de noviembre, de protección patrimonial de las personas con discapacidad).

Pero quizás lo más importante, al menos pensando en clave de política europea, fue la adopción del primer plan de acción europeo en materia de discapacidad. Aunque el mismo no fue tan ambicioso como nos hubiera gustado en aquel momento, es indiscutible que supuso un paso cualitativo de gran relevancia, en la medida en que nos ofreció una plataforma para hacer avanzar la política europea de discapacidad de una manera más rápida y eficaz.

El plan de acción, formulado a través de la comunicación de la Comisión titulada Igualdad de oportunidades para las personas con discapacidad: un plan de acción europeo definió cuáles eran los objetivos que la UE se marca en materia de discapacidad para el periodo 2003-2008. En aquellos momentos la primera prioridad era asegurar la plena aplicación de la directiva relativa a la igualdad de trato en el empleo, cosa que la Comisión consideraba debía anteponerse a la consideración de nueva legislación específica, como es el caso de la directiva marco sobre discapacidad por la que el movimiento europeo de la discapacidad apostó fuertemente en aquellos momentos y sigue apostando actualmente.

La segunda gran prioridad comunitaria en aquellos momentos era la de integrar adecuadamente las cuestiones de discapacidad en las políticas comunitarias pertinentes, esto es, el mainstreaming, con especial atención a las políticas relacionadas con el empleo, ya que la Comisión Europea consideraba, acertadamente creo yo, que el empleo era la mejor forma de introducir mejoras duraderas para las personas con discapacidad y de lograr su plena inclusión en la vida social. Quince años después desgraciadamente lo continúa siendo. Es por ello por lo que se comprometía a prestar especial atención a la integración de las cuestiones de discapacidad en las políticas relacionadas con el empleo, en particular en el ámbito de la educación y el aprendizaje permanente.

Finalmente, la Comisión Europea estimaba que especial atención debía ser prestada al tema de la accesibilidad, y más concretamente al principio del "diseño para todos", por considerar, de manera acertada de nuevo, que la accesibilidad de los bienes, los servicios y el entorno construido es un aspecto esencial para la integración de las personas con discapacidad que concierne. En este sentido y continuando la línea de acción que había marcado ya en el año 2000 con la ya célebre comunicación Hacia una Europa sin barreras para las personas con discapacidad (Comunicación de la Comisión Europea al Consejo, al Parlamento Europeo, al Comité Económico y Social y al Comité de las Regiones. Hacia una Europa sin barreras para las personas con discapacidad, COM(2000) 284 final, de 12 de mayo de 2004.), la Comisión se comprometió a promover la elaboración de normas técnicas europeas, de documentos de normalización y de otras orientaciones de carácter más general para traducir en términos técnicos el concepto de "accesibilidad para todos", el cual es un elemento de trascendental importancia para potenciar la integración de las personas con discapacidad en la vida económica y social. Igualmente, el ejecutivo comunitario se comprometía a fomentar los esfuerzos encaminados a sensi- 
bilizar a los responsables en materia de normalización sobre el concepto de "accesibilidad para todos" y sobre las oportunidades existentes en el mercado. No hay que olvidar que las personas con discapacidad suponen un mercado muy importante al que, incluso si se mira desde una perspectiva empresarial, no se puede ser ajeno.

Mirado con la perspectiva que dan los quince años que han pasado desde la publicación de ese primer plan europeo de discapacidad (2003-2010), se han realizado avances pero los desafíos a los que el mismo quería hacer frente continúan, y en algunos casos hasta se han agravado, como por ejemplo en el ámbito del empleo, en donde la crisis ha hecho que la mayor parte de los avances realizados durante una década se hayan ido al garete.

\section{La Estrategia Europea de Discapacidad}

En clave política el instrumento fundamental es la llamada Estrategia Europea de Discapacidad, que es el marco político que da cobijo a distintas iniciativas comunitarias, tanto de naturaleza legislativa como de soft law, relativas a la discapacidad. Fue el 15 de noviembre de 2010 cuando la Comisión Europea presentó la Estrategia Europea sobre Discapacidad para esta década, que se encuentra ya en su recta final (2020). La misma sucede al Plan de Acción de Discapacidad que estuvo vigente entre 2003 y 2010.

Esta Estrategia proporciona un marco de acción a escala europea y nacional con el objetivo de que las personas con discapacidad puedan disfrutar de todos sus derechos y beneficiarse plenamente de una participación en la economía y la sociedad europeas.

La Estrategia se centra en la eliminación de barreras e identifica medidas a escala de la UE complementarias a las acciones a nivel nacional. También determina los mecanismos necesarios para aplicar la Convención de Naciones Unidas sobre los Derechos de las Personas con Discapacidad en la Unión Europea y expone el apoyo necesario para la financiación, la investigación, la sensibilización, la recopilación de datos y la elaboración de estadísticas en materia de discapacidad.

Antes de entrar en detalles sobre la Estrategia Europea de Discapacidad, permitidme un breve inciso sobre la Convención, por si algunos no estáis familiarizados con la misma. Se trata de un documento histórico y un punto de inflexión en el reconocimiento de los derechos de las personas con discapacidad en tanto que derechos humanos. Fue adoptada por la Asamblea General de las Naciones Unidas en 2006 y se trata del primer tratado internacional de derechos humanos ratificado por la UE en tanto que persona jurídica, siendo por tanto parte del ordenamiento jurídico comunitario y también nacional.

\subsection{Principales ámbitos de actuación}

La Comisión identifica ocho ámbitos principales de actuación en la Estrategia. Además de las acciones previstas a nivel europeo, la Comisión también apoyará las medidas nacionales a favor de las personas con discapacidad en cada uno de estos ámbitos. Los ámbitos de actuación prioritarios son: 


\subsubsection{Accesibilidad}

- Por 'accesibilidad' se entiende el acceso de las personas con discapacidad, en las mismas condiciones que el resto de la población, al entorno físico, al transporte, a las tecnologías de la información y la comunicación (TIC), y a otras instalaciones y servicios. La directiva sobre la accesibilidad de los sitios web aprobada en 2016 va en esa dirección, aunque se quedó corta en ambición.

- El objetivo de la Comisión es garantizar la accesibilidad a los bienes y servicios, en especial a los servicios públicos y los dispositivos de apoyo para las personas con discapacidad. En este sentido, la Comisión propone entre otras cosas utilizar instrumentos legislativos y de otro tipo, como la normalización, para optimizar la accesibilidad al entorno construido, el transporte y las TIC. También se fomentará la incorporación de la accesibilidad y el "diseño para todos" en los planes de estudios educativos y de formación profesional de las profesiones pertinentes y se potenciará un mercado de la UE para tecnologías de apoyo.

- Asimismo, en aquel momento la Comisión se comprometió a estudiar la posibilidad de proponer un Acta de Accesibilidad Europea para 2012, que podría englobar el desarrollo de normas específicas para determinados sectores. Fue finalmente en 2015 cuando así hizo, propuesta que está tres años después aun en tramitación legislativa con riesgos de quedar vaciada de contenido.

\subsubsection{Participación}

- El objetivo en este ámbito es lograr una plena participación en la sociedad de las personas con discapacidad, permitiéndoles disfrutar de todos los beneficios de la ciudadanía de la UE, suprimiendo las trabas administrativas y las barreras a la participación y proporcionando servicios de calidad de ámbito local que comprendan el acceso a una ayuda personalizada.

- Entre otras cosas, la Comisión se comprometía a:

- Trabajar en la superación de los obstáculos al ejercicio por parte de las personas con discapacidad de sus derechos como personas, consumidores, estudiantes o actores económicos y políticos. Por ejemplo, se está abordando la cuestión de la accesibilidad del voto.

- Abordar los problemas relacionados con la movilidad interna de las personas con discapacidad en la UE, por ejemplo, facilitando y promoviendo el uso de un modelo europeo de tarjeta de estacionamiento para personas con discapacidad, cosa que hoy es ya una realidad.

- Promover la transición de un modelo de asistencia institucional a una asistencia de carácter local mediante el uso de los Fondos Estructurales y del Fondo de Desarrollo Rural. Avances importantes han sido conseguidos a día de hoy, aunque queda aún bastante por hacer, sobre todo en los países del este de Europa.

- Mejorar la accesibilidad de organizaciones, actividades, actos, instalaciones bienes y servicios, comprendidos los de tipo audiovisual, en los campos del deporte, el ocio, la cultura y la diversión.

- Promover la participación en actos deportivos y la organización de actos específicos para las personas con discapacidad. 
- Estudiar las maneras de facilitar el uso de la lengua de signos y del alfabeto Braille en los contactos con las instituciones europeas. El Parlamento Europeo adoptó una declaración escrita sobre un sistema voluntario para el etiquetado en Braille para los productos industriales hace unos años, pero aparte de esto no soy consciente de grandes avances.

- Promover la transferencia transfronteriza de obras protegidas por derechos de autor en un formato accesible e intensificar el uso de las excepciones que admite la Directiva europea sobre derechos de autor. En esto sí que se ha avanzado significativamente a través de la reciente ratificación del Tratado de Marrakech y su posterior incorporación al ordenamiento jurídico comunitario.

\subsubsection{Igualdad}

- Uno de los objetivos de la Estrategia es erradicar la discriminación por razón de discapacidad en la UE. Para ello, la Comisión se compromete a utilizar la legislación europea vigente en materia de no discriminación y además a aplicar una política activa destinada a luchar contra la discriminación y promover la igualdad de oportunidades en todas las políticas de la UE.

- La Comisión también se compromete a prestar una atención especial al impacto acumulativo de la discriminación que pueden experimentar las personas con discapacidad, si se suman otros motivos de discriminación como la nacionalidad, la edad, la raza o el origen étnico. Es lo que también se denomina "discriminación múltiple".

- $\quad$ Además, la Comisión incluye entre sus prioridades velar por la plena aplicación de la Directiva de no discriminación en el empleo, favorecer la diversidad y luchar contra la discriminación a través de campañas de sensibilización a escala nacional y de la UE, y apoyar la labor de las ONG que trabajan en este terreno.

\subsubsection{Empleo}

- La Comisión quiere posibilitar que el mayor número posible de personas con discapacidad tenga ingresos por actividades laborales en el mercado de trabajo 'abierto' y contribuir así también a la consecución de los objetivos en materia de empleo que se ha fijado la UE. Es aquí donde se establece el vínculo más directo con la Estrategia UE2020. En este sentido, la Comisión se comprometió a:

- Explotar el pleno potencial de la Estrategia Europa 2020 y de su Agenda de nuevas cualificaciones y empleos.

- Dar a conocer mejor la situación de las mujeres y los hombres con discapacidad respecto al empleo, identificar retos y proponer soluciones.

- Prestar especial atención a los jóvenes con discapacidad en su transición de la educación al empleo.

- Abordar la movilidad interna en el mercado laboral 'abierto' y en talleres protegidos a través del intercambio de información y del aprendizaje mutuo.

- Tratar la cuestión de las actividades por cuenta propia y de los empleos de calidad. 
- Intensificar su apoyo a las iniciativas voluntarias que promuevan la diversidad en el lugar de trabajo, tales como "Cartas de la diversidad" firmadas por la empresa o iniciativas de empresa social.

- A destacar el componente económico (a mayor empleo de personas con discapacidad más integración social y menos gasto público).

\subsubsection{Educación y formación}

- El objetivo en esta área es promover una educación y un aprendizaje permanente inclusivos para todos los alumnos con discapacidad.

- Además, la Comisión dedica recursos a difundir información sobre los niveles educativos y las oportunidades que se ofrecen a las personas con discapacidad, y busca aumentar la movilidad de estas personas facilitando su participación en el Programa de aprendizaje permanente, Programa Erasmus, etc.

\subsubsection{Protección social}

- En líneas generales, el objetivo en esta área es promover unas condiciones de vida dignas para las personas con discapacidad, que deben poder beneficiarse de los sistemas de protección social y de los programas de reducción de la pobreza, de ayudas a la discapacidad, de planes de vivienda pública y de otros servicios de facilitación, así como de programas de prestaciones y jubilación. La Comisión ha prestado atención a estos asuntos a través de la Plataforma europea contra la pobreza, lo que incluye evaluar la adecuación y sostenibilidad de los sistemas de protección social y de las ayudas del Fondo Social Europeo.

\subsubsection{Sanidad}

- El objetivo en esta área es potenciar la igualdad de acceso para las personas con discapacidad a los servicios sanitarios y a las instalaciones vinculadas. Para ello la Comisión:

- Apoya el desarrollo de medidas encaminadas a la igualdad de acceso a la asistencia sanitaria que comprendan unos servicios sanitarios y de rehabilitación de calidad diseñados para las personas con discapacidad.

- Presta una atención especial a las personas con discapacidad a la hora de poner en práctica medidas destinadas a luchar contra las desigualdades en el campo de la salud.

- Promueve la adopción de medidas en el ámbito de la salud y la seguridad en el trabajo para reducir los riesgos de sufrir una discapacidad durante la vida laboral y mejorar la reinserción laboral de los trabajadores con discapacidad. La discapacidad sobrevenida cada vez cobra una mayor importancia. De ahí el interés de este punto. 


\subsubsection{Acción exterior}

Finalmente, con el objetivo de promover los derechos de las personas con discapacidad en la acción exterior de la UE, la Estrategia Europea de Discapacidad incluye el compromiso de la Comisión Europea de:

- Trabajar en un marco más amplio de no discriminación para hacer hincapié en la discapacidad como un componente de los derechos humanos en la acción exterior de la UE.

- Realizar labores de sensibilización con respecto a la Convención de Naciones Unidas sobre los Derechos de las Personas con Discapacidad y las necesidades de las personas con discapacidad en el campo de las actuaciones de emergencia y la ayuda humanitaria.

- Consolidar una red de corresponsables en materia de discapacidad en las delegaciones exteriores de la UE.

- Garantizar que los países candidatos potenciales o efectivos a la adhesión a la UE (que en estos momentos incluyen países como Montenegro, Albania, Serbia o Bosnia) avancen en la promoción de los derechos de las personas con discapacidad y se asegurarse de que los instrumentos financieros destinados a las ayudas previas a la adhesión se utilicen para mejorar la situación de este colectivo.

- Fomentar los acuerdos y compromisos sobre cuestiones de discapacidad en foros internacionales (Naciones Unidas, Consejo de Europa, OCDE).

\subsection{Puesta en práctica de la Estrategia Europea de Discapacidad}

Con el fin de cumplir dichos objetivos, la Comisión cuenta con los siguientes instrumentos generales para la puesta en práctica de la Estrategia:

1. Sensibilización: concienciar a la sociedad de todo lo referente a la discapacidad e informar en mayor medida a las personas con discapacidad de sus derechos y la manera de ejercerlos, prestando particular atención a la accesibilidad de los materiales y los canales de información.

2. Apoyo financiero: optimizar el uso de los instrumentos de financiación de la UE para favorecer la accesibilidad y la no discriminación y aumentar la visibilidad de las posibilidades de financiación en los programas posteriores a 2013 en lo que se refiere a la discapacidad. Con la perspectiva que nos da el paso del tiempo y en tanto que testigo directo gracias al Programa Operativo del Fondo Social Europeo que gestionamos en Fundación ONCE creo que se ha avanzado significativamente. La reforma de los fondos estructurales que está ya en marcha de cara al periodo 2021-2027 nos ofrece la oportunidad de conseguir nuevos avances.

3. Estadísticas y recopilación y seguimiento de datos: se ha desarrollado una encuesta específica sobre barreras a la integración social de las personas con discapacidad, pero a mi modo de ver no hemos avanzado a la velocidad que deberíamos. La falta de datos exhaustivos y comparables es un hándicap importante a la hora de abogar por políticas más ambiciosas en beneficio de las personas con discapacidad. Afortunadamente en España hemos avanzado en este campo gracias a los trabajos del INE, aunque aún queda camino por recorrer. 
4. Establecimiento de los mecanismos que requiere la Convención: a escala de la UE se han establecido mecanismos de coordinación entre los servicios de la Comisión y el resto de las instituciones de la UE, así como entre la UE y los Estados miembros. También se ha incluido un marco de seguimiento que incluya un mecanismo independiente para fomentar, proteger y supervisar la aplicación de esta.

\section{Antecedentes, fundamento y alcance del pilar social}

Paso ahora a analizar el presente y el futuro en materia de política social, que no es otro que el pilar social, adoptado con gran solemnidad por los líderes europeos el 17 de diciembre de 2017 en Gottemburgo (Suecia). Comienzo por los antecedentes. La idea de crear un pilar europeo de derechos sociales fue anunciada por el presidente Juncker en su discurso sobre el Estado de la Unión de 2015 y presentada por la Comisión en abril de 2017, tras la pertinente consulta pública en los distintos estados.

El pilar social se basa en el artículo 3 del Tratado de la Unión Europea, el cual establece que los objetivos de la Unión son, entre otros, promover el bienestar de sus pueblos y trabajar por el desarrollo sostenible de Europa basado en un crecimiento económico equilibrado y la estabilidad de precios, una economía de mercado social competitiva, con el objetivo de pleno empleo y el progreso social y un alto nivel de protección y mejora de la calidad del medio ambiente. La Unión deberá combatir la exclusión y la discriminación, promover la justicia social y la protección, la igualdad entre mujeres y hombres, la solidaridad entre generaciones y la protección de los derechos del niño.

También se basa en la Carta de los Derechos Fundamentales de la Unión Europea, proclamada en el Consejo Europeo de Niza del 7 de diciembre de 2000 y en diversos preceptos del Tratado de Funcionamiento de la Unión Europea relativos a la libertad de circulación de los trabajadores (artículos 45 a 48), el derecho de establecimiento (artículos 49 a 55), la política social (artículos 151 a 161), la promoción del diálogo social (artículo 154), incluidos los acuerdos celebrados y aplicados a nivel de la Unión (artículo 155), la igualdad de remuneración entre hombres y mujeres por igual trabajo (artículo 157), la contribución al desarrollo de la calidad educación y formación profesional (artículos 165 y 166), la acción de la Unión que complementa las políticas nacionales y fomenta la cooperación en el ámbito de la salud (artículo 168), la cohesión económica, social y territorial (artículos 174 a 178), la formulación y la vigilancia de la implementación, de las líneas generales de las políticas económicas (artículo 121), la formulación y el examen de la aplicación de las directrices para el empleo (artículo 148) y, más en general, la aproximación de la legislación (artículos 114 a 117).

Como señalaba anteriormente, en el pilar social no se reconocen jurídicamente nuevos derechos como se ha querido presentar por algunos medios de comunicación. En realidad, los 20 'derechos' que se proclaman no son vinculantes sino meramente declarativos, ya que en realidad dependerán de las legislaciones de cada Estado miembro y de su voluntad de establecerlos, desarrollarlos y/o garantizar su efectividad.

Además, en los documentos y declaraciones que acompañaron la proclamación del pilar social no se incluyen nuevas medidas legislativas que no estuviesen ya sobre la mesa. Más bien se trata de un 'refrito' de iniciativas existentes, entre las que se encuentran: 
- El Acta Europea de Accesibilidad.

- Revisión de la Directiva sobre Trabajadores Desplazados.

- Legislación para ampliar el permiso de paternidad.

- Legislación sobre seguridad e higiene en el trabajo.

- Legislación para modernizar las normas de coordinación de los sistemas de seguridad social.

- Creación de una Autoridad Laboral Europea.

- Legislación para impulsar la implementación de la Garantía Juvenil.

Tampoco se desbloquean fondos adicionales, sino que se hace referencia al Fondo Social Europeo y al Fondo Europeo de Inversiones Estratégicas.

Por todo lo anterior, el valor del pilar social es principalmente simbólico, al lanzar un mensaje, potente en la forma, sobre la voluntad y compromiso político de no olvidar lo que antes se llamaba la dimensión social de la Unión Europea y que pasó a segundo plano, si no desapareció, durante los años de la crisis económica. Ahora toca avanzar en este campo.

6. Catálogo de derechos 'reconocidos' por el pilar social

A continuación, enumero los veinte derechos 'reconocidos' por el pilar social. Insisto, el pilar social no reconoce jurídicamente nuevos derechos, contrariamente a lo que han publicado algunos medios. Solamente tiene un valor político y declarativo. Es un listado un poco largo, pero creo que merece la pena enumerarlos, porque ilustran bien cuáles son las prioridades políticas europeas en materia de política social, al menos sobre al papel.

1. Educación, formación y aprendizaje permanente: todos tienen derecho a una educación inclusiva y de calidad, formación y aprendizaje permanente para mantener y adquirir competencias que les permitan participar plenamente en la sociedad y gestionar con éxito las transiciones en el mercado laboral.

2. Igualdad de género: a) La igualdad de trato y oportunidades entre mujeres y hombres deben ser asegurados y fomentados en todas las áreas, incluyendo la participación en el mercado laboral, las condiciones de empleo y la promoción profesional. b) Las mujeres y los hombres tienen derecho a igual salario por trabajo de igual valor.

3. Igualdad de oportunidades: independientemente del sexo, origen racial o étnico, religión o creencia, discapacidad, edad u orientación sexual, todos tienen derecho a la igualdad de trato y oportunidades en materia de empleo, protección social, educación y acceso a bienes y servicios disponibles para el público. Se fomentará la igualdad de oportunidades de los grupos subrrepresentados.

4. Apoyo activo al empleo: a) Todos tienen derecho a una asistencia adecuada para mejorar las perspectivas de empleo o de autoempleo. Esto incluye el derecho a recibir apoyo para la búsqueda de empleo, 
capacitación y recualificación. Todos tienen derecho a conservar la protección social y los derechos de formación durante las transiciones profesionales. b) Los jóvenes tienen derecho a la educación continua, aprendizaje, prácticas o una oferta de trabajo de buena calidad tras cuatro meses de estar desempleado o dejar la educación. c) Las personas desempleadas tienen derecho a una atención personalizada, continua y un apoyo adecuado. Los parados de larga duración tienen derecho a una evaluación individual en profundidad a más tardar a los 18 meses de desempleo.

5. Empleo seguro y adaptable: a) Independientemente del tipo y la duración de la relación laboral, los trabajadores tienen derecho a un trato justo y equitativo con respecto a sus condiciones de trabajo, acceso a la protección social y capacitación. Se fomentará la transición hacia formas abiertas de empleo. b) De conformidad con la legislación y los convenios colectivos, deberá asegurarse la flexibilidad necesaria para que los empleadores se adapten rápidamente a los cambios en el contexto económico. c) Deben fomentarse las formas innovadoras de trabajo que garanticen condiciones de trabajo de calidad Se debe estimular el espíritu empresarial y el trabajo por cuenta propia. La movilidad profesional debe ser facilitada. d) Se evitarán las relaciones de trabajo que conducen a condiciones de trabajo precarias, incluso prohibiendo el abuso de los contratos típicos. El período de prueba debe ser de una duración razonable.

6. Salario: a) Los trabajadores tienen derecho a salarios justos que proporcionen un nivel de vida decente. c) Se garantizará un salario mínimo adecuado, que proporcione la satisfacción de las necesidades del trabajador y de su familia, teniendo en cuenta las condiciones nacionales económicas y sociales, y salvaguardando el acceso al empleo y los incentivos para buscar trabajo. Debe prevenirse la pobreza en el trabajo. d) Los salarios se establecerán de forma transparente y predecible de acuerdo con las prácticas nacionales y respetando la autonomía de los interlocutores sociales.

7. Información sobre condiciones de empleo y protección en caso de despido: a) Los trabajadores tienen derecho a ser informados por escrito al comienzo del empleo sobre sus derechos y obligaciones derivados de la relación laboral, incluido el período de prueba. b) Antes de cualquier despido, los trabajadores tienen derecho a ser informados de los motivos y se les otorgará un período de aviso razonable. Tienen derecho a acceder a un servicio efectivo e imparcial de resolución de conflictos y, en caso de despido injustificado, el derecho a reparación, incluida una compensación adecuada.

8. Diálogo social y participación de los trabajadores: a) Se consultará a los interlocutores sociales sobre el diseño e implementación de las políticas económicas, laborales y sociales de acuerdo con las prácticas nacionales. Se les alentará a negociar y concluir acuerdos colectivos en asuntos relevantes para ellos, respetando su autonomía y el derecho a la acción colectiva. Cuando resulte apropiado, los acuerdos celebrados entre los interlocutores sociales se aplicarán a nivel de la Unión y sus Estados miembros. b) Los trabajadores o sus representantes tienen derecho a ser informados y consultados a su debido tiempo sobre asuntos relevantes para ellos, en particular sobre la transferencia, reestructuración y fusión de empresas y sobre los despidos colectivos. c) Se fomentará el apoyo a que los interlocutores sociales tengan una mayor capacidad en el diálogo social.

9. Conciliación del trabajo y la vida: Los padres y las personas con responsabilidades de cuidado tienen el derecho a una licencia adecuada, flexibilidad en el trabajo y acceso a servicios de atención. Las mujeres y los hombres tendrán igual acceso a servicios especiales, permisos para cumplir con sus responsabilidades de cuidado,

10. Trabajo saludable, seguro y bien adaptado. Medio ambiente y protección de datos: a) Los trabajadores tienen derecho a un alto nivel de protección de su salud y seguridad en el trabajo. b) Los trabajado- 
res tienen derecho a un entorno de trabajo adaptado a sus necesidades profesionales y que les permita prolongar su participación en el mercado laboral. c) Los trabajadores tienen el derecho a la protección de sus datos personales en el contexto laboral.

11. Cuidado y apoyo de los niños: a) Los niños tienen derecho en la primera infancia a una educación asequible y de buena calidad. b) Los niños tienen derecho a la protección contra la pobreza. Los niños de entornos desfavorecidos tienen el derecho a medidas específicas para mejorar la igualdad de oportunidades.

12. Protección social: sin importar el tipo y la duración de su relación laboral, los trabajadores y, en condiciones comparables, los trabajadores por cuenta propia, tienen derecho a una protección social adecuada.

13. Beneficios del desempleado: los desempleados tienen derecho a un apoyo de activación adecuado por parte de los servicios públicos de empleo para (re)integrarse en el mercado laboral y a prestaciones de desempleo adecuadas de duración razonable, en consonancia con sus contribuciones y reglas nacionales de elegibilidad. Tales beneficios no deberán representar un desincentivo para un retorno rápido al empleo.

14. Ingresos mínimos: todos los que carecen de recursos suficientes tienen derecho a ingresos mínimos adecuados que garanticen una vida digna en todas las etapas de la vida, así como el acceso efectivo a bienes y servicios. Para quién puede trabajar, los ingresos mínimos deben combinarse con incentivos para (re)integrarse en el mercado laboral.

15. Ingresos y pensiones de vejez: a) Los trabajadores y los trabajadores por cuenta propia jubilados tienen el derecho a una pensión acorde a sus contribuciones que asegure un ingreso adecuado. Las mujeres y los hombres deberán tener las mismas oportunidades para adquirir derechos de pensión. b) En la vejez todos tienen derecho a los recursos que les aseguren la vida en dignidad.

16. Cuidado de la salud: todos tienen derecho a un acceso oportuno a servicios asequibles, así como a atención médica preventiva y curativa de buena calidad.

17. Inclusión de personas con discapacidad: las personas con discapacidad tienen derecho a un apoyo de ingresos que garantice vivir con dignidad, servicios que les permitan participar en el mercado de trabajo y en la sociedad, y un entorno de trabajo adaptado a sus necesidades.

18. Cuidado a largo plazo: todos tienen derecho a servicios de cuidado a largo plazo asequibles y de calidad, en particular servicios domiciliarios y comunitarios.

19. Vivienda y asistencia para personas sin hogar: a) Se proporcionará a los necesitados el acceso a la vivienda social o la ayuda para obtener una vivienda de buena calidad. b) Las personas vulnerables tienen el derecho a que se les proporcione asistencia y protección contra el desalojo forzoso. c) Se proporcionará un refugio y servicios adecuados a las personas sin hogar para promover su inclusión social.

20. Acceso a servicios esenciales: Todos tienen derecho a acceder a bienes y servicios esenciales de calidad, incluidos agua, saneamiento, energía, transporte, servicios financieros y comunicaciones digitales. El apoyo a tales servicios estará disponible para quienes lo necesiten. 


\section{La discapacidad en el pilar social}

La discapacidad ocupa un espacio relevante en esta declaración, en concreto en dos derechos, el $3^{\circ}$ y el $17^{\circ}$. $\mathrm{Y}$, también de forma indirecta, en el $5^{\circ}$. Evidentemente, y aunque no se diga, la discapacidad es un elemento que atraviesa todos y cada uno de los derechos.

En el primero (el $\left.3^{\circ}\right)$, en el marco del derecho a la igualdad de trato y oportunidades en materia de "empleo, protección social, educación y acceso a bienes y servicios disponibles para el público" de una serie de grupos de población, que incluye un mandato a fomentar la igualdad de oportunidades "de los grupos subrepresentados".

En cuanto al segundo, se trata de un derecho (el $5^{\circ}$ ) específicamente dedicado a la "inclusión de personas con discapacidad" y tiene por objeto instar a que se garantice, por una parte, un "apoyo de ingresos", lo que se podría traducir en una renta mínima. Por otra parte, el derecho a contar con 'servicios' que les permitan a las personas con discapacidad participar en el mercado de trabajo y en la sociedad y "un entorno adaptado a sus necesidades".

Finalmente, se hace una referencia genérica en el derecho 5 a) al fomento de "la transición hacia formas abiertas de empleo", que bien pudiera ser aplicable a las fórmulas de empleo protegido.

\section{Instrumentos europeos para el desarrollo y la materialización de la política social}

Una vez pintada la fotografía del ámbito objetivo de la política social europea, lo siguiente es detenernos brevemente a analizar qué instrumentos están a disposición de la Unión Europea para implementar esa política. Aunque no existe una categorización oficial, yo hablaría de siete, a saber:

- Legislación de la UE. Se explica por sí misma. Las directivas de no discriminación son un ejemplo de ello. Obviamente a los que estamos en el mundo social nos gustaría que Bruselas aumentase su actividad legislativa en el ámbito social.

- Diálogo social: el diálogo social europeo, una de las piedras angulares del modelo social europeo, desempeña un papel fundamental en la elaboración e implementación de la Agenda Social Europea. EI derecho de los interlocutores sociales a ser consultados antes de cualquier iniciativa de la Comisión en materia de empleo o de asuntos sociales, a negociar las cuestiones presentadas por la Comisión o a celebrar acuerdos autónomos por iniciativa propia, consagrado por el Tratado CE, ha tenido numerosos resultados positivos, como sus acuerdos sobre el permiso parental, la violencia y el estrés en el trabajo, el teletrabajo o los mercados inclusivos.

- Método abierto de coordinación: el método abierto de coordinación, aunque quizás esté aún menos vigente hoy en día, ha sido un instrumento importante en la medida que ayuda a los Estados miembros 
a desarrollar una visión compartida de los retos sociales, favorece la voluntad de cooperar y aprender de las prácticas de los demás. El mismo generó un nuevo dinamismo para promover y aplicar reformas, y está fomentando la elaboración de políticas más basadas en el conocimiento, orientadas a la apertura, la transparencia y la participación de todas las partes interesadas, aspecto este último fundamental si queremos conseguir políticas eficientes y efectivas.

- Financiación de la UE: el principal instrumento financiero europeo para la implementación de la política social de la UE son los fondos estructurales y, en particular, el Fondo Social Europeo. Estos fondos y programas están en fase de revisión de cara al nuevo periodo presupuestario 2021-2027, estando así en juego en gran parte la financiación de la dimensión social del proceso de integración europeo. Para el nuevo periodo presupuestario la Comisión Europea propone asignar 101 billones de euros al FSE. Aunque la prioridad principal del mismo es la formación y la generación de empleo, el nuevo FSE+ asignará un $25 \%$ de los fondos totales a materia de inclusión social. Esperamos que España reciba un $5 \%$ más que en el anterior periodo presupuestario.

- Asociación, diálogo y comunicación: este instrumento se refiere principalmente a los partenariados, tanto entre administraciones públicas como entre las mismas y otros actores como empresas u organizaciones de la sociedad civil (ONG, interlocutores sociales, etc.). El rationale no es otro que dada la enormidad de la tarea que las administraciones públicas no pueden hacer frente por sí solas, todos los recursos que se puedan apalancar para el cumplimiento de las prioridades sociales, ya sean económicos o humanos, han de ser bienvenidos.

- Garantizar que todas las políticas de la UE promuevan las oportunidades, el acceso y la solidaridad: Se refiere al mainstreaming de la perspectiva social en todas las políticas e iniciativas europeas.

- Semestre Europeo: es como se conoce al mecanismo de coordinación de las políticas económicas y financieras, que forma parte del marco de gobernanza económica de la Unión Europea. Durante el Semestre Europeo los Estados miembros ajustan sus políticas presupuestarias y económicas a los objetivos y normas acordados a escala de la UE. El gasto en política social de los Estados miembros es parte de esta ecuación, de ahí la importancia del Semestre Europeo para la política social. Como curiosidad se llama 'Semestre' porque se centra en los primeros seis meses de cada año.

\section{A modo de conclusión}

A modo de conclusión, creo que debo finalizar este análisis con una mirada crítica, eso sí constructiva, de la dimensión social en el proceso de integración europeo.

Creo que hay que felicitarse de la iniciativa de la Comisión Europea de lanzar el pilar social y de involucrar a toda la sociedad civil en su definición. Esto en si no cabe duda de que ya de por si es positivo. No obstante, no se puede obviar que al fin y al cabo hay una distribución de competencias entre la Unión Europea y los Estados miembros que hace que al final la pata social sea responsabilidad principal de estos últimos. Lo mismo ocurre con la financiación. Leyes ambiciosas en el ámbito social no funcionan si no van acompañadas de la dotación presupuestaria necesaria, como experimentamos aquí en España por ejemplo con la Ley de 
Dependencia. Es esta obviamente una de las limitaciones del pilar social como lo fue en su momento del método abierto de coordinación y que hace que, por mucho que se hagan grandes declaraciones políticas defendiendo una Europa social, luego los mismos no se traduzcan en iniciativas concretas que cambien para mejor la vida de los ciudadanos europeos, sobre todos aquellos más desfavorecidos.

En segundo lugar, el hecho de que un año después de la adopción del pilar social no se haya avanzado en la tramitación legislativa de dosieres concretos como es el caso del proyecto de directiva de igualdad de trato, me genera dudas importantes de hasta qué punto el pilar social va a ser verdaderamente un punto de inflexión en la creación de una Europa más social. Otro ejemplo de asimetría entre las palabras y los hechos es el caso del Acta Europea de Accesibilidad, que no solamente lleva un lustro de retraso sobre el calendario legislativo inicialmente previsto, sino que en las negociaciones entre el Parlamento y el Consejo está siendo vaciada de contenido y de la ambición inicial. En noviembre de 2018 ambas instituciones acordaron un texto de compromiso que deja fuera del ámbito jurídico de la norma la accesibilidad del entorno construido y establece plazos transitorios para su entrada en vigor que corren el riesgo de convertirla en una iniciativa que no contribuya de manera significativa al cambio social que buscaba.

Otro ejemplo es la falta de apoyo para la aprobación de un Plan de Acción Europeo para la Promoción de la Economía Social, un sector que se ha mostrado especialmente resistente durante la crisis, manteniendo el empleo y contribuyendo activamente a la inclusión social.

En tercer lugar, considero que el pilar social debe promover y potenciar los alcances sociales existentes, así como su aplicación total. En otras palabras, como bien sabemos hay mucha legislación que ha sido ya aprobada pero que en gran parte no está siendo aplicada apropiadamente e incluso en algunos casos es papel mojado. La Carta de Derechos Fundamentales es un ejemplo. Otro ejemplo, en este caso relativo a la discapacidad, estamos viendo como legislación tan importante que debería estar ya plenamente en vigor como la Convención de las Naciones Unidas sobre los Derechos de las Personas con Discapacidad, no está siendo debidamente implementada.

Por otro lado, creo que no se está abordando lo sistemáticamente que se debería el futuro del trabajo. En mi opinión es una de las áreas que necesita especial atención porque los avances tecnológicos nos van a llevar a un nuevo paradigma con nuevos desafíos sociales, algunos de gran calado. Este fenómeno ha sido estudiado en profundidad por la Organización Internacional del Trabajo (OIT) y como botón de muestra cito el Informe 03/2018 El futuro del Trabajo, del Consejo Económico y Social de España (CES, 2018, Colección Informes).

Otro frente que me preocupa especialmente, en tanto que antiguo director del Gabinete Técnico de la Secretaría General de la Seguridad Social aquí en España, y que debería recibir más atención a nivel comunitario es el de la protección social, más allá de la mera coordinación de los sistemas de seguridad social para facilitar la movilidad laboral. El desarrollo de sistemas de protección social que sean sostenibles, eficaces y eficientes es fundamental para el mantenimiento del modelo social europeo. Y yo diría aún más, son claves también para el futuro del propio proceso de integración europeo.

En cuanto a nivel más macro, considero que es imperativo que se aborde un debate serio sobre la arquitectura y la gobernanza de la Unión Económica y Monetaria. Sus debilidades estructurales nos exponen en mayor 
medida a nuevas crisis como de la que estamos aun recuperándonos. $Y$ como hemos sufrido en nuestras propias carnes en época de crisis lo social pasa aún más si cabe a un segundo plano.

Finalmente, a mi modo de ver debe permitirse una mayor involucración de la sociedad civil y de los agentes sociales en la definición e implementación de las políticas sociales, entre los que se encuentra el sector fundacional al que pertenezco, que pienso deben jugar un papel importante durante todo el proceso, tanto de diseño como de aplicación del pilar social.

En fin, resumiendo, la proclamación del pilar social es una buena noticia, pero no tan buena como desde la UE y desde la prensa se nos ha querido hacer ver. Supone una oportunidad y un impulso que debemos saber aprovechar para traducir esa supuesta voluntad política en iniciativas concretas ambiciosas en distintos ámbitos, tanto a nivel nacional como europeo. 


\section{Referencias bibliográficas}

Comisión Europea. Propuesta de directiva por la que se aplica el principio de igualdad de trato entre las personas independientemente de su religión o convicciones, discapacidad, edad u orientación sexual, $\operatorname{COM(2008),~} 2$ de Julio de 2008, pp. 426 final (en línea). <https://eur-lex.europa.eu/legal-content/ES/TXT/HTML/?uri=CELEX:52 008PC0426\&from=ES $>$, acceso 28 de mayo de 2019.

Comisión Europea. Comunicación al Consejo, al Parlamento Europeo, al Comité Económico y Social y al Comité de las Regiones. Hacia una Europa sin barreras para las personas con discapacidad, COM(2000) 284 final, 12 de mayo de 2004 (en línea). <https://eur-lex.europa.eu/LexUriServ/LexUriServ.do?uri=COM:2000:0284:FIN:ES :PDF>, acceso 28 de mayo de 2019.

Comisión Europea. Comunicación de la Comisión sobre la igualdad de oportunidades de las personas con minusvalía. Una nueva estrategia comunitaria en materia de minusvalía. COM(1996) 30 de julio de 1996, pp. 406 final (en línea). <http://ec.europa.eu/employment_social/soc-prot/disable/com406/406-es.pdf>, acceso 28 de mayo de 2019.

Consejo Económico y Social (CES) (2018): Informe 03|2018. El futuro del trabajo. Madrid: Consejo Económico y Social (en línea). <http://www.ces.es/documents/10180/5461461//nf0318.pdf>, acceso 28 de mayo de 2019.

España. Real Decreto Legislativo 1/2013, de 29 de noviembre, por el que se aprueba el Texto Refundido de la Ley General de derechos de las personas con discapacidad y de su inclusión social, Boletín Oficial del Estado, 3 de diciembre de 2013, núm. 289, pp. 95635-95673.

España. Ley 39/2006, de 14 de diciembre, de Promoción de la Autonomía Personal y Atención a las Personas en Situación de Dependencia. Boletín Oficial del Estado, núm. 299, 15 de diciembre de 2006, pp. 44142-44156.

España. Ley 51/2003, de 2 de diciembre, de igualdad de oportunidades, no discriminación y accesibilidad universal de las personas con discapacidad. Boletín Oficial del Estado, 3 de diciembre de 2003, núm. 289, pp. 43187-43195 (en línea). <https://www.boe.es/buscar/act.php?id=BOE-A-2003-22066>, acceso 28 de mayo de 2019.

España. Ley 41/2003, de 18 de noviembre, de protección patrimonial de las personas con discapacidad. Boletín Oficial del Estado, de 19 de noviembre de 2003, núm. 277, pp. 40852-40863 (en línea). <https://www.boe.es/ buscar/act.php?id=BOE-A-2003-21053>, acceso 28 de mayo de 2019

Naciones Unidas (2006): Convención Internacional sobre los Derechos de las Personas con Discapacidad. Nueva York: ONU. 